\title{
Putting the Event in its Place: territories, bodies, thresholds
}

\section{Colocando o Acontecimento no seu Lugar: territórios, corpos, limiares}

\begin{abstract}
Resumo:
O objetivo desse artigo é repensar o conceito de acontecimento e de lugar do acontecimento como um ambiente relacional de imanência ocupado pela invenção em seu processo emergente, com referência na obra de Deleuze e Guatarri, Massumi, Simondon e Whitehead. Os territórios são entendidos como ações, extensões condicionadas de relações que vão além de um discurso sobre internalismo/ externalismo: são mapeamentos de limites difusos, zonas gradativas de intensidades relacionais. Os corpos (humanos e não humanos) não são mais entidades estáticas préconstituídas, mecanicamente interagindo entre si; eles se tornam individuações dinâmicas de relações de causalidade recíprocas e recursivas no campo da experiência. Nas intersecções das sobreposições de territorializações e corpos, os limiares devem ser cruzados por solidárias-operações próprias. Deste modo, o acontecimento se torna um todo imanente e coerente, onde o processo de vir-a-ser requer uma convergência espaço-temporal, um contemporâneo de territórios e corpos com seus meios associados.

Palavras-chave: Acontecimento. Territórios. Corpos. Limiar. Meio associado.
\end{abstract}

\begin{abstract}
:
The purpose of our paper is to re-conceive the event and the site of the event as a relational environment of immanence occupied by invention in its processual emergence using the work of Deleuze and Guatarri, Massumi, Simondon and Whitehead. Territorialities are understood as active, conditioned expanses of relation that go beyond the internalism/ externalism debate: they are mappings of fuzzy-bounded, gradated zones of relational intensities. Bodies (human and non-human alike) are no longer pre-constituted static entities mechanically interacting with each other; they become dynamic individuations of a reciprocal, recursive relational causality within fields of experience. At the intersection of overlapping territorializations and bodies, thresholds must be crossed for the operative-self-solidarity to take place. Thus, the event becomes an immanent, coherent whole, where the process of coming-to-being requires a spatiotemporal convergence, a contemporaneous coming together of territories and bodies within the associated milieu.

Keywords: Event. Territories. Bodies. Threshold. Associated milieu.
\end{abstract}

REBOLLEDO, Felix. Putting the event in its place: territories, bodies, thresholds. Informática na Educação: teoria \& prática, Porto Alegre, v. 15, n. 1, p. 31-43, jan./jun. 2012.
Felix Rebolledo

Concordia University

f I ask you to visualize a room, you would likely imagine four walls, a floor and a ceiling. You will likely add a door so you can enter the room and a window to let in the sunshine and fresh air. You will decorate and furnish it and you will likely eventually envision yourself or people you know engaged in some activity or other within it. Thus, your conception of the room would likely entail physical boundaries, a contained volume and an intended useso that reduced to its barest essentials, we can imagine the physically bounded volume to take on any form we wish; the walls, floor and ceiling can assume any shape or material we desire; and, we can dedicate this space to whatever use we fancy. With these suppositions we can engage this Pandora's box of ideas to reflect on fundamental questions dealing with space, place and our participation in actuality in terms of the event. They force us to consider questions dealing with the concept of the container, what delimits the container, and that which is contained.

We as Westerners usually understand space in terms of a Euclidian 3-D space because it 
is the one we feel we understand implicitly and most accept intuitively as our model of physical reality, specially seeing how we have learned to reify it perceptually. We refer to space as Euclidian because its construction conforms with the intelligible geometrical depiction of space as laid out in Euclid's Elements and the manifestation of its geometrical truths concur with our sensible understanding of actuality. The room is a simple and neat example of a spatial container; the walls, floor and ceiling isolate, delineate, outline, demarcate, confine, impound, enclose and contain a closed volume of space that can be understood perceptually as having depth, width, height. If we abstract the room and conceive it as a cube sitting in space, we end up with an enclosed volume-a hollow, distinct, stand-alone entity-that is differentiated from the surrounding space by its hard-sided boundaries. This enclosed parcel of space which has length, breadth and depth and contained within space is referred to as a place, especially when we can relate its location to another place. As such, a "place" can be defined in a number of ways: by the volume contained, by the inside surfaces that are in contact with and contain the volume, by the outside surface of the entity which is in contact with the space that surrounds it, and by the "hollowed" volume in space which confines and allows the entity to occupy that space. The room can also be understood in any of these ways, i.e. it can be seen either as the physical limit of the enclosed volume of space as separate from that which contains it, as in a room or the room, or it can be seen as that which is contained within the limits of the physical boundary, room as in room to move. The difference between a room and a place is that a place is a more or less open yet delimited expanse of location for activity whereas the usual conception of a room requires that it be closed. As such, each defini- tion presents different ways of understanding the limit function of that which occupies place and how it goes about doing so. However, we must bear in mind that this sets up a very significant implicit duality of inclusion/exclusion, i.e. of inside/outside, between that which is contained and that which contains it: to paraphrase Deleuze and Guattari, it represents the binary segmentarity of the dualist opposition of inside and outside (DELEUZE; GUATTARI, 2007 [1987], p. 208). Place seems to want to make the spatial distinction between the location of that which is happening and that which is not in terms of activity (thereby bringing in aspects of temporality into the mix) whereas room seems to make the objectifying distinction between that which is contained and that which contains it in terms of a static, purely geometric understanding of space. In this paper, we will be using the term place as a generic subset, an enclosed volume of space.

In order to locate place in space, to establish its location, we make recourse to a relative coordinate system. Greek mathematicians had developed an objective volumetric conception of objects as having length, width and depth but they had not made the leap to a locatory description of place within space in terms of the locus of coordinates measured off on orthogonal axes. Relative location is derived from an extension of Descartes' planar paired coordinate system into a coordinate system involving three dimensions: we set up three intersecting orthogonal planes which in turn create three orthogonal lines or axes where pairs of planes intersect. We define location relative to an arbitrary Origin-the point where the three planes intersect-from which we can metrically specify relative position between different entities as measurements, dimensions along the axes in Euclidian 3-D space $\left(E^{3}\right)$. The origin, the " 0 " point for the metric determination of any local coordi- 
nate systems is arbitrary and can be established anywhere we wish. Even so, in order to identify the location of a thing or as an event $x$, one has to identify some motionless point of reference and Newton understood this requisite in order to postulate his dynamics. To make this work, he situates space within an intelligible absolute, abstract, ideal void that is eternal, unchanging, ungenerated and indestructible; it allows its overcoding and gridding (DELEUZE; GUATTARI, 2007 [1987], p. 212). This void simultaneously permeates and engulfs sensible space and renders it into a determinate whole. This absolute emptiness is infinitely extended, homogenous and isotropic both spatially and temporally yet inconceivable in its totality: it homogenises both space and time thereby allowing their consistent metrical expression. This establishes the limit of the place/space relation of actuality. i.e. that which contains that which contains that which contains, ad infinitum as contained and container where that which encloses and contains space is understood in terms of a theosophic construction that characterizes genesis and teleology as well as the mechanics of causality, potentiality and necessity through divine intervention.

In this conception of space we have a clear notion of spatial and temporal location in that they are regular modalities which reflect the qualities of the homogenous, isotropic and infinitely extended absolute space. Time is a one-dimensional, independent variable which functions as a Euclidian linear entity, $E^{1}$, and ranges over the $E^{3}$ space so that given two points, $x$ and $x^{\prime}$, "i.e. two different events, we have a well-defined notion of their spatial separation, namely the distance between the points $x$ and $x^{\prime}$ of $\mathrm{E}^{3}$, and we also have a welldefined notion of their time difference, namely the separation between $t$ and $t^{\prime}$ as measured in $E^{1 "}$ (PENROSE, 2007, p. 385). So that given two events in space, we have a clear notion of the distance between the two events, as well as a clear notion of their temporal separation, i.e. the time interval between them. According to this model, all events, everything that happens, literally, 'takes place' within space; all activity-all that which exists as an event-happens within the confines of the cosmic container and is fully determinable and determinate as an entity that is separate and distinct from that which bounds and isolates it. Given this striated space, all events $x_{n}$ are fully determinable and in their place and result from a cause and effect linear causality. "It is a space in which objects are situated independently of the presence of subjects" (LEMAY; STEINER, 2010 , p. 939) so that there's a me-subject and an it-object i.e. an event, that exist as objectified, fully-determined, stand-alone entities. However, we do not normally conceive of the event as a point in space at a given time; we usually understand the event as a concrescence of point-events at a specific location which share a duration.

If we jump from the abstract space of mathematics into a more general consideration of the event and of space within this conception, the event can be seen to be in a place, i.e. as enclosed within the volume created by the space that circumscribes it or spatially contained by the walls of the room that create a place for it. The intended use of the room, its teleological intention, usually defines the event that takes place in it-the simple act of naming its purpose, i.e. labelling it, immediately conditions its use. This might seem like a trivial statement but the functional conditioning of the label is often ingrained more deeply than we realize. For example, the installation "The Empty Museum" by Russian artists Ilya and Emilia Kabacov shown at the $5^{\text {th }}$ Mercosul Bienal in Porto Alegre, Brazil in 2007 illustrates this deep conditioning rather well. 
"The piece reconstructs a true-to-life exhibit room from a traditional museum in a room at the Bienal: all the details such as decoration, furniture and illumination are in place, except that there are no "pictures" on the walls. Although the walls of the installation are empty, with illumination highlighting where the "pictures" should be, the viewers engage the environment and exhibit of "missing pictures" in the same way as if there were "pictures" on the wall" (OLIVEIRA; REBOLLEDO, 2011, p. 220).

A gallery is a place where the only thing to be done is to look at pictures on the wall; a movie theater is the place where the only thing to be done is to look at a movie on a screen; a classroom is a place where the only thing to be done is to listen to the lecturer. It is interesting to note that no other activity is likely to be allowed that detracts from the primary one i.e. no talking, no eating, etc. In this respect, the label acts as an order-word, as an envelope for the implicit pre-conditions contained by the name as an assemblage of enunciations which "designate this instantaneous relation between statements and the incorporeal transformations on non-corporeal attributes they express" (DELEUZE; GUATTARI, 2007 [1987], p. 81).

Usually the simple label applied to a place is sufficient to define its use and curtail its possibilities. It conditions how it is going to be used and defines what kinds of relations can be entertained in the space: one does not eat in the living room, nor does one play ball in the kitchen. The simple act of naming the room creates "a virtual, conditioned spatial container for the event-and it is not simply of containing it in terms of creating boundaries with walls for the event, but by providing a place-holder for the disposition of the unfolding continuity of the event as a subset of all possible relations." Paraphrasing Massumi (2009), the label constitutes "the set of mediating actions shepherding the abstractly thought object into concrete embodiment" (MASSUMI, 2009, p. 7).
However, this also implies that the activities in term of relations that happen, that take place, in a room are what define it: that which goes on inside is what enables us to label it. It tells us that whatever activity as an expression of relation we choose to entertain is what gives ultimate meaning to the room either as a spatial unfolding, i.e. taking up room, or as a temporal unfolding, i.e. going on, or as a combination of both as taking place. A sign placed on the wall next to the entrance to a room or on the door as an identifier of a room's purpose (laboratory, bedroom, broom closet, classroom) preconditions and limits the room's potential as to its use; we can extend this idea to the labels used to designate areas on an architectural drawing: the l.r. is not the d.r. and not the master b.r. Hence, a sign such as "Topological Media Lab" on the door or the wall next to its entrance consciously subverts this kind of conditional limitation to the ideation of the space and its uses by proclaiming that the room as a volume is likely the most simplistic projection of the expression of unbounded and varied possibility within.

Take for example any empty room with blank walls. As an environment, its potential is unlimited in terms of "housing" an event. As we dress it, adorn it, decorate it and fill it with objects that condition and occupy the space, its degrees of freedom in terms of what can and cannot be done in that space will be curtailed. This occupation will define the functionality of the room, reduce its options and limit its potential in terms of its ability to express occupational possibility not only in terms of volume but in terms of what activities can literally take place within it: by adding a bed, a dresser, a bedside table, a lamp, etc. we will eventually conclude that we have a "bedroom". As we add furnishings to a room, the combination of these occupations will result in a label establishing an operational solidarity, 
not the result of a simple step-by-step accumulation, or of a piecemeal adding together of elements. It is non-decomposable. It is holistic. It's not a structure... It does not add elements together to form a structural unity. Rather, it is a holism effect that adds a whole new dimension of existence to the elements' diversity (MASSUMI, 2009, p. 11).

The room itself, as four walls, has now become almost irrelevant other than it allows for the simple location of the event, and what we are doing is moving towards composing the room not as a spatial, volumetric construction but as the location that houses the expression of the relations that are being created in their perduration, a place. Hence, that which constitutes the place of the event-the taking-upspace within the room-is not the room qua room in terms of physical containment, but the locus of participation created by neighbourhoods of relational occupation where the homeostasis afforded by participation sustains the meta-stable tension between that which takes place and that which gives room. The locus of inclusion is easy to conceive as the body of the event and its shape is the manifestation of the event itself at the simple location where it takes place in its unfolding. Yet, the locus of inclusion is open-the relational composition of the event requires it in spite of the fact that we comprehend the event as a self, contained, as a self-contained individualization.

During the fall term of 2010, every second Wednesday afternoon, a group of students, new media researchers, artists and philosophers would gather at the Topological Media Lab in EV-725 at Concordia University for a seminar on Memory and Architecture. If we consider this seminar as an event, how can actualize "the locus of inclusion created by neighbourhoods of relational participation as process" in terms of this gathering?

The event is a dynamic cohesion-though not necessarily continuous-composed of the inter-penetration of the immanent co-arising of territorialities and bodies. Territorialities can be understood as active, material and non-material conditioned expanses of relation that go beyond the internalism/externalism debate: they are open, fuzzy-bounded, gradated zones of relational intensities where that which conditions constitutes ingression and cohesion. Perhaps the easiest ones to establish are the material conditioning environmental modalities of the encounter. Even though there is a multiplicity of these territorialities, we can identify several major ones that condition the space of relation. Obviously, the room EV-725 constitutes the major set of environmental territorializing preconditions but we would like to add several that are relevant and indispensable in conditioning the event: the disposition of the research stations and work desks; the chalk board at one end of the room; the conference table; the couches around the table; the windows along two walls; the halogen lighting suspended from the grid over the conference table... Merely by occupying the space, by filling up the volume of the room, they restrict movement, limit degrees of freedom, curtail the potential of what can be done in the room: they induce relation in specific ways. The relations that are imposed between these environmental constituents as active participants not only condition how and where the seminar can take place and how the human participants can move within the room, but they colour the event itself in that all participants will engage each other as a function of the relational preconditions established by the spatial disposition of these material accessories or inductions. For example, the discussion that a formally relaxed environment affords will be more open and parrhesiastic than one where the form of address is one-to-many or where round-table debate happens in a more 
official and "proper" setting. This is not to say that the setting of TML activities is not "proper", but that the way that space is occupied and apportioned preconditions the event, i.e. it communicates a specificity to that which can unfold as activity in that space. The conference table is an attractor that encourages the convergence of attention and conditions the modality of relation and exchange between the human participants, if anything, because it is the only location in the room that will allow a dozen people to congregate for discussion. Yet, given the openness of the room and the comings and goings of other researches involved in their own activities in other parts of the room, the seminar as an event can in turn be related to these other events: its importance is relativized to other happenings in the room that allow it to stand out as a distinct individualization from all others-it becomes one-event-among-many and not the-one-andonly event at that time. And though this "democratic" deployment of activity might seem disruptive to some, TML researchers understand the concurrent cohabitation of discussion and creative conceptualization with electronic music composition, programming, hanging out, project coordination, academic writing, etc. as the immanent civitas or commonwealth of research-creation in the making. The ethics that emerges up to now is "content-free" in that only the furniture and accessories as deployed throughout the room have significantly pre-conditioned the modalities of relation during the seminar and have drawn the human participants to engage in relation in a specific way. We would be remiss at this point if we neglected to underline that this relational inter-conditioning is at the basis of the continuity of actuality that Whitehead would call the extensive continuum: without that, this cannot be; without this, that cannot be-this inter-conditioning can be extended to infini- ty so that an organic continuity of relational process is established throughout as a continuum. But perhaps the most important aspect of this analysis is that these furnishings considered as participants in the event not only take up space, they, in conjunction with the human participants, are cause and attribute to the creation of the event: as such, they constitute and express immanence "as the unity of efficient and formal cause" (DELEUZE, 1992, p. 165) where causality can no longer be seen as the result of linear cause and effect but as an interdependent co-arising.

In considering the TML's volumetric extension as a room, the room qua room, is almost irrelevant to the conception of our event other than in the consideration of capaciousness as the ability to accommodate the numerous activities at the TML conducted on an ongoing basis. The delimitation of place created by the relational occupation of the table, the chairs, the sofas and the suspended halogens does not only designate the location for discussion but constitutes a set of material inductions that can be seen abstractly but in a concrete way as an intersection of territorializations of potential engagements constituting the event as an open, fuzzy-bounded, gradated zone of relational intensities. And although the space of the event is open, the event taking place around the table is "contained" by participation in the shared experience at hand and understood as an individualization that stands out from the "background" constituted by non-participant researchers, their activities, sundry material accoutrements and beyond. Yet, in spite of this local intensification of relation which expresses itself as an individuation, the inter-connectedness of the continuum is maintained; only the mapping, the attentional focus, need be changed to bring out en relief a new event. However, considering the event as an individuation is not question of rende- 
ring it a static object: the event as such will never exhaust its infinite potential. "Individuation must be understood as the becoming of being, and not as a model of being that would exhaust its signification" (SIMONDON, 2009, p. 13). The seamless, organic process of individuation as the becoming of being in terms of relational movement is the "eventual" unfolding of actuality.

Thus far, the seminar we've been attempting to portray as an event as the locus of inclusion, as an open-bodied, fuzzy-bounded, concrescence of inter-penetrated territorialities expressed in terms of gradated zones of intensities has only been formulated through considerations of a material nature. Obviously, the event is not exclusively determined by material inductions alone; there are environmental and experiential inductions to consider which inflect the unfolding of the event as well as the role of human participants. In the same way that the furniture and accessories in the TML conditioned the event even though they were indirectly or peripherally implicated in the event, the temperature of the room or the amount of sunshine pouring in through the windows condition not only the cominginto-being of the event but its unfolding and duration as well. Examples of experiential preconditioning that will impact on the seminar's unfolding could include reading an entry posted on the seminar's blog, a discussion over tea by two of the participants the week before the seminar, a question asked in a class the day before the seminar, or a bad case of indigestion in one of the participants the morning of the seminar. Material and experiential preconditions have temporal and proximal values attached to them: their impact will be weighted according to values of intensity in terms of spatial and temporal distance. Although the impact of these non-immediate conditioning inductions might be deemed irrelevant or unim- portant to the unfolding of the actual event, they underscore the temporal expression of the intensification of the event as a gradual processual coming-into-being over time. The nature of these inductions-material, non-material, environmental, experiential, etc-all act in concert and are often difficult to differentiate one type from another. The important thing to retain is that they have a participatory role in the constitution of the event's unfolding.

What about the human participants? How does the "me" enter into experiential relation in the seminar as an event? In order to answer these questions, instead of preserving the "I" as an entity, as an unchanging, objective identity, we need to think in terms of activities of relations. The words "I" or "me" refer to a continual re-inventing of the self, to the continuous production of new relational entities, as that which create new modes and states of relation not only with each other, but with the environmental inductions of the event by dynamically (actively in motion) engaging each other. Although we have been referring to the human participants as preconstituted entities, the preconstituted "I" as a participant in the event does not per se exist. Instead, the seminar-participating "me" can be seen as the dynamic, indeterminate plurality of the continuous reconstitution of relations as an individualization within fields of experience. This indeterminate plurality of relations is deemed a body, not in terms of a human body, nor in its "simple materiality, by its occupying space ('extension'), or by organic structure. It is defined by the relation of its parts (relations of relative motion and rest, speed and slowness), and by its actions and reactions with respect both to its environment or milieu and its internal milieu" (BAUGH, 2005, p. 31). And for each and every participant in the seminar, human and non-human alike, we can say the same thing. Whether human or not, they car- 
ry the same democratic participatory heft in establishing the event qua event. Territorialities entrain, captivate and entrance bodies into relation by "grounding" or "preconditioning" the reciprocal recursive causality of relations that are setting up the incipient experiential event taking hold as an individuation, as a body at the level of species. It becomes a "system of individuations, an individuating system and a system individuating itself" (SIMONDON, 2009, p. 7). The event becomes an immanative, dynamic, coherent whole, a body composed of a multiplicity of bodies informed by enabling constraints, inflected by disparate physical and non-physical inductions through their effects and their abilities to enter into relation. Here, participants are environmental, human, material or affective: they are physical and non-physical alike where "Participation... is the fact of being an element in a greater individuation..." (SIMONDON, 2009, p. 9).

Usually, the event as a significant occasion is defined as a happening taking place at a particular location and at a particular time, where entering the designated location and starting the event at the scheduled time serve as thresholds that must be "crossed" for the event's coming-into-being as an individuation. However, it is not only the approach to the designated location at the designated time that cue us to the incipient event. In the same way that experiential inductions guide and inform the gradual formation of the event, environmental and architectural inductions gradually prepare us for what awaits us. For example, if we take a large, spacious room with high ceilings and a wooden floor and we annex a room containing lockers, showers and toilets, we will likely guess what kind of activities, behaviours and relations will be "permitted" once we enter the big room. If instead we annex a room whose walls are lined with counters and mirrors surrounded by lights, our relation to the adjoining space will be conditioned in a different way. An annex of this type that conditions our expectations as to what to expect in the next contiguous space is a transition: it is a portal that announces what is about to happen and serves as an indication of potential relations on the verge. Crossing the doorway between the hallway outside the TML into the contained volume of the lab at the designated time can be said to perform the same function but in a more generic and nondescript way. This "instantaneous" crossing of the threshold that fails to consider the gradual coming-tobeing of the event is part of the conception of the objectified event and of the inside/outside duality. At best, it can be said to stand-in or symbolise the crossing from that which gradually conditioned and built-up the relational potential and its expression beyond-as in the time-worn cliché where the groom carries the bride through the threshold. A gate or arch is more descriptive, i.e. a richer expression, of that which constitutes crossing the threshold in terms of what can be expected beyond as often illustrated by the "Gates of Chinatown" in Montreal, San Francisco, Incheon or Manchester. Their ornamental narrativity provides the gradual transition from one environment to the next.

In our seminar example, wending our way through the crowds of the main floor of the EV building, taking the elevator to the seventh floor, knocking at the door of the TML, waiting for someone to open the door, greeting the researcher that has opened the door, and making our way to the conference table constitute transitional territorialisations and de-territorializations which in themselves constitute mini-events contributing to the coming-to-being of the seminar-event as one line of convergence among many: for example, the territorialisation of the shaking hands mini-event inside the TML is feasible as a re- 
sult of the de-territorialization, of the disbanding, of the standing-in-the-hallway-waiting event. As such, the succession of convergent territorialisations (and prior and subsequent de-territorializations) of moving bodies is a better expression of the constitution of the event-a process that "conserves within itself a permanent activity of perpetual individuation" (SIMONDON, 2009, p. 7). The process of coming-to-being requires the concurrent coming together, the spatio-temporal convergence, of territories and bodies as constitutive subsidiary events. In the Deleuzian conception of the event qua event, the event is more than just a noteworthy happening, even though it does work in this sense as well. If I present the seminar-event here as the dynamic becoming-conjunction of specific environmental, social and intellectual bodies and inducements we have to keep in mind that the equation is not a simple sum, it is not $a+b+$ $c+d=$ the event as one, but where the variables' participation in the relation is what dynamically defines them as they simultaneously instigate their own becoming and create an individuation that is different and greater than the sum of its parts-the event is a unity that is more than one, "more than unity and more than identity" (SIMONDON, 2009, p. 6). Yet, the event as such, as an individualization, is a process of limitation which is characterised as a gradation. (WHITEHEAD, 1985, p. 162) The gradation is a relational intensification where its heft in terms of concretization can only be defined as a threshold: in the event of day giving way to night, the point in time where day actually becomes night is very difficult to define, though we know when night has come. As the gradual intensification of night overwhelms day, we realize that a threshold has been crossed when it is no longer day and we stand in the darkness of night. We can arbitrarily define a measurable threshold that will define night, e.g. a measure of the intensity of light, but in terms of the event, we can describe the coming of night as the sun going down, the appearance of stars in the sky, the substitution of the sea breeze by a land breeze, workers heading home after work, families preparing for dinner, children preparing for bed, etc. But even in this mundane example, we can see that the constituent territorialities and bodies as actual occasions defining the event are imbued with disparate temporalities of gradated intensification and duration which are themselves entrained into the concrescence here understood as day giving way to night. Once territorialities and bodies actually engage and interpenetrate they can be said to enter into relational participation in the event as an overwhelming, as a beyond the threshold. At the intersection of overlapping territorializations and bodies, thresholds must be crossed in order that the individualization can be deemed accomplished. At each juncture, the threshold "interposes itself between two diversities, whose discontinuity it marks by a change in intensity accompanied by a qualitative change in the defining properties of the system." The threshold is both spatial and temporal: it marks "that moment at which the system makes the leap into operative-selfsolidarity" (MASSUMI, 2009, p. 12). And once the experiential threshold has been crossed, in that the participants have come into relation and the event is in full formation, "we must recognize not only the genesis of what participates, but also of what is participated itself, which accounts for the fact of its being participated" (DELEUZE, 1992, p. 171).

The event as an emergent amalgam of territorialities and bodies acquires and expresses its own spacetime within which participants become associated as one in the experiential milieu that involves them. In French, the term milieu does not only refer to a physical envi- 
ronment or setting, it means "surroundings," or a "medium" as in chemistry, or as "middle." The milieu is normally understood as the ensemble of external conditions within which a living being lives and develops or as the assemblage of material objects and physical circumstances which surround and influence an organism. Conceptually, "milieu" can also be seen as an environment in the widest ecological sense of the term, i.e. as the locus of the dynamic interaction of all the factors and mechanisms that participate in the sustenance of an ecosystem. To paraphrase Massumi (DELEUZE; GUATTARI, 2007 [1987], p. XVII), the term milieu should be read as a technical term combining all these meanings.

The concept of the associated milieu, conceived by French philosopher Gilbert Simondon in his book Du mode d'existence des objets techniques (SIMONDON, 1989), is a useful model to analyze the co-arising relationships that take place between the participants and the conditioning territorialities as an environment. The descriptive term "associated" when applied to describe milieu refers to a specific mapping of an ensemble made up of constitutive elements and conditioning environmental modalities which come together to create an individuation through the ongoing exchanges of energy that take place within that specific milieu (SIMONDON, 1989, p. 57).

The milieu allows for a reciprocal recursive relational causality to take place between the elements so that we may conceive of spacetime as the immanent plane from which the subject and object arise as the generic activity of passing from the objectivity of the data to the subjectivity of the actual entity as a process. "The associated milieu sustains, unites and brings together bodies: it is not a stage upon which a scene unfolds, or a play where only the actors perform, or a canvas upon which the pigments run into each other, or a manuscript where the words follow each other in sequence." (OLIVEIRA, 2010, p. 29). The associated milieu is the setting and environment of concretion where participants condition each other in order to form something which in turn, simultaneously, allows these very same things to take form themselves. In other words, the milieu allows for a non-static, dynamic coming-to-being as an event of taking-form as experience. According to Deleuze and Guattari: "The notion of the milieu is not unitary: not only does the living thing continually pass from one milieu to another, but the milieus pass into one another; they are essentially communicating" (DELEUZE; GUATTARI, 1987, p. 313).

The taking place of the event is a conditioned coming-into-being that is pre-disposed by the order-word or label applied to the event, though the event is up to a point predefined by the label, the event in its entirety is not definable as the constituting relata are not totally knowable. This label provides causal traction and gives direction to the event although its shape, its body is only determinable in the event's unfolding. Whitehead calls the active, relational process of fulfilling the label's telos the "satisfaction" - "The notion of 'satisfaction' is the notion of the 'entity as concrete' abstracted from the 'process of concrescence'; it is the outcome separated from the process... which is both process and outcome" (WHITEHEAD, 1985, p. 84). Although the processual unfolding of the event is preconditioned by the satisfaction as a "lure", its actual unfolding is anything but determined and its final outcome will be the expression of the event. The label that we accord to the event and its unfolding is not only the name of the event as an objectified entity but serves as the attractor or seed-Whitehead's lure for feeling-as that which incites "the basic generic operation of passing from the objectivity of the data to the 
subjectivity of the actual entity in question" (WHITEHEAD, 1985, p. 40). The move towards satisfaction allows concrescence within the super-saturated environment of relational potential and results in the "intensification of 'formal immediacy'" (WHITEHEAD, 1985, p. 88). This super-saturation, this over-concentration, of potential-coming-together at the intersection of inter-penetrated myriad territorialities and bodies results in the event expressed as a manifestation of excess, of coming-togetherbrimming-over the containment of inclusion.

In order to think the event in this way, as an emergent interconnected relationality, we would need to think its spatial container differently as well as its process of becoming in a different way: what would an immanent spacetime be like? It would be just like the actual "reality" we live in now except that the way we would speak ontologically about it would be different. We would need for the "space" aspect to be self-contained, so that there is no interior/exterior duality to the conception of space; the "time" aspect would need to be incorporated as an expression of space, so that there's no need for its expression as an independent dimension. It is a spacetime in which we can speak in terms of objects and subjects where they interdependently co-arise immanently in the event so that there's no me-subject over here and an it-object, i.e. an event, over there that exist as fully-determined, stand-alone entities: their immanence is based on an interdependent causality where the intensities of relation within each territoriality expresses their own temporality.

In the 300 years since Newton, mathematics and geometry have proposed new conceptions of space which have been corroborated by the empirical findings of physics. The principal breakthrough in this regard is Riemmanian non-Euclidian geometry. It allows us think of space as four dimensional and allows for the inter-penetration of space and time into a self-contained, unbounded expanse. Space and time become spacetime where events can be described not as static points as in the Newtonian conception of space but as a field of tensors or directed lines of intensity which incorporate time. For example, one can propose a flat 4-D sphere of infinite diameter upon which actuality can be mapped as the relation and interaction of intensities that can manifest themselves as localized compressions and distensions of spacetime which as topological mappings can be resolved as individuations.

The event as an open, yet bounded, set of participative relations defines itself in terms of an association of gradated intensities as an immanent causality of becoming which allow us to speak of a fuzzy-bounded cloud as the body of the event. This type of mapping allows us to ask afresh Spinoza's question "what can a body do?"-not necessarily in human terms, but in the non-human terms of the event. This would require a topological conception of the event and it would allow us to consider the geometry of location, place and space in a new way: as a cohesive, though not necessarily continuous, multidimensional grouping of relations that can be variously mapped according to homotopic correspondences where concepts such as cohesion, proximity, neighbourhood, ingression and continuity can be applied with greater precision. 


\section{References}

BUGH, B. Body. Entry in The Deleuze Dictionary. Edited by Adrian Parr. New York: Columbia University Press, 2005.

CASEY, E. S. Smooth space and rough-edged places: The hidden history of place. The Review of Metaphysics. December 1997, Vol. 51. No. 2. pp. 267-296. Accessed 30.09.2010 10:38 from http://www.jstor. org/stable/20130200

DELEUZE, G. Expressionism in Philosophy: Spinoza. Translated by Martin Joughin. New York: Zone Books, 1992.

DELEUZE, G. Spinoza: Practical Philosophy. Translated by Robert Hurley. San Francisco: City Lights, 1988.

DELEUZE, G.; GUATTARI, F. A thousand plateaus. Capitalism and schizophrenia. Translated by Brian Massumi. Minneapolis: University of Minnesota Press, 2007 [1987].

LEMAY, C.; STEINER, P. Beyond the internalism/externalism debate: The constitution of the space of perception. In Consciousness and Cognition 19, 2010. 938-952. Obtained directly from Pierre Steiner 17.11.2010.

MASSUMI, B. "Technical Mentality" revisited: Brian Massumi on Gilbert Simondon. With Arne De Boever, Alex Murray, and Jon Roffe. Parrhesia Journal. 2009 No. 7, 36-4. Accessed 10.11.2010 from: http://www. parrhesiajournal.org/parrhesia07/parrhesia07_massumi.pdf

MASSUMI, B. Parables for the Virtual: Movement, Affect, Sensation. Durham: Duke University Press, 2002.

OLIVEIRA, A. Corpos Associados: interatividade e tecnicidade nas paisagens da arte. Doctoral Thesis. Porto Alegre: UFRGS, 2010.

OliVeirA, A.; ReBOlledo, F. The Associated Milieu: A Machinic Assembly between Artwork and Viewer. The Journal of Arts in Society, volume 5, numero 5, 2011, pp. 217-223.

PENROSE, R. The Road to Reality: A Complete Guide to the Laws of the Universe. New York: Vintage Books, 2007.

SIMONDON, G. The Position of the Problem of Ontogenesis. Translated by Gregory Flanders. Parrhesia Journal. 2009 No. 7, 4-16. Accessed 10.11.2010 from:

http://www.parrhesiajournal.org/parrhesia07/parrhesia07_flanders.pdf 
SIMONDON, G. Du mode d'existence des objets techniques. Paris: Éditions Aubier, 1989.

SPINOZA, B. Ethics. Translated by E.M. Curley. London: Penguin Books, 1994.

WhITEHEAD, A.N. Process and Reality: An Essay in Cosmology (Corrected Edition). New York: The Free Press, 1985.

Recebido em: 13 de outubro de 2011

Aprovado para publicação em: 21 de novembro de 2011

\section{Felix Rebolledo}

M.A. student in Philosophy and Cinema Studies in the Specialized Independent Program at Concordia University, Montreal, Canada. E-mail: felix@studio514.ca 